\title{
THE EFFECT OF NaOH AND KOH ON THE CHARACTERIZATION OF MESOPOROUS AIOOH IN THE SOLVOTHERMAL ROUTE
}

\author{
FARHAD SALIMI*, "MOZAFFAR ABDOLLAHIFAR*, ALI REZA KARAMI** \\ *Department of Chemical Engineering, College of Science, Kermanshah Branch, \\ Islamic Azad University, Kermanshah 67131, Iran \\ **Department of Chemistry, College of Science, \\ Shahid Rajaee Teacher Training University, Tehran 13761, Iran \\ "E-mail: abdollahifar@gmail.com
}

Submitted March 21, 2016; accepted July 24, 2016

\begin{abstract}
Keywords: Boehmite, Solvothermal, $\mathrm{NaOH}, \mathrm{KOH}, \mathrm{Nanostructure}$
In this study boehmite nanostructures have been successfully synthesized using solvothermal method at $180^{\circ} \mathrm{C}$ and at high basic $\mathrm{pH}(\sim 13.5)$, when ethanol was as solvent. The effects of $\mathrm{NaOH}$ and $\mathrm{KOH}$ as $\mathrm{pH}$ adjusting regents on the characterization of synthesized samples were investigated in detail. X-ray powder diffraction (XRD), Fourier transform infrared spectroscopy (FTIR) and field emission scanning electron microscopy (FESEM), were used to characterize the samples. The specific surface area, pore size distribution and pore structure of the different boehmite structures at different condition were also discussed by the $\mathrm{N}_{2}$ adsorption/desorption test. According to our experimental results, the FESEM micrographs show that the samples synthesised by $\mathrm{NaOH}$ and $\mathrm{KOH}$ are nanostructure and nanoparticles, respectively. The obtained boehmite nanostructure from NaOH exhibited large surface area of $144 \mathrm{~m}^{2} \cdot \mathrm{g}^{-1}$ and high total pore volume of $1.28 \mathrm{~cm}^{3} \cdot \mathrm{g}^{-1}$.
\end{abstract}

\section{INTRODUCTION}

Various metal oxyhydroxides nanostructures with different morphologies and characteristics have been extensively synthesized with various methods and received much attention in recent years [1-3]. These nanostructures have great potential in applications in adsorbents, ceramics, and catalysts. On the other side, nanostructure materials also provide large surface areas compared with their micro and macro counterparts. Owing to these, several researches have broadly addressed to develop new methods to prepare oxyhydroxides nanostructures [1-11]. Among these, boehmite $(\mathrm{AlOOH})$ has attracted extensive attention because of their nontoxic and low cost characteristics for many applications [12-17].

Synthesis method has an important effect on properties and characterizations of material products. Conventional processes for synthesizing boehmite nanostructures include sol-gel [18], precipitation [19], hydrothermal $[20,21]$ and solvothermal [22] and other related routes [23]. Among the reported synthetic routes, solvothermal technique have been broadly employed as the effective method do to the mild synthesis conditions and flexible change of experimental parameters. In this method, the synthesis conditions, such as solvent [24], reaction temperature and time [20], solution $\mathrm{pH}$ [25], adding surfactants [26] and $\mathrm{pH}$ adjusting regent [10] have great effects on the structure and character of boehmite.

To our best knowledge, the synthesis of boehmite via solvothermal route in different $\mathrm{pH}$ adjusting regents have not been reported. In this paper, we present a facile route for the fabrication of high surface area boehmite nanostructures.

\section{EXPERIMENTAL}

The starting materials utilized are $\mathrm{Al}\left(\mathrm{NO}_{3}\right)_{3} \cdot 9 \mathrm{H}_{2} \mathrm{O}$, $\mathrm{NaOH}, \mathrm{KOH}$ and ethanol $96 \%$, were purchased from Scharlau, Spain, and used as received without further purification.

In a typical process, $10 \mathrm{~g}$ Aluminium nitrate was dissolved in $120 \mathrm{ml}$ of ethanol, and it was stirred for 15 min at room temperature. $\mathrm{NaOH}$ or $\mathrm{KOH}$ solution ( 2 Molar) was subsequently added drop by drop to the solution to give lacteous precipitates immediately. At this point, the $\mathrm{pH}$ value of the reaction mixture was $\sim 13.5$, then transferred into Teflon-lined stainless steel autoclave $\left(200^{\circ c}\right)$, and heated at $180^{\circ} \mathrm{C}$ for $24 \mathrm{~h}$. These samples were treated by centrifugation, rinsed with ethanol several times, and then dried at $60^{\circ} \mathrm{C}$ in an oven for $48 \mathrm{~h}$. The boehmite samples prepared by $\mathrm{NaOH}$ and $\mathrm{KOH}$ were labelled $\mathrm{N}-\mathrm{B}, \mathrm{K}-\mathrm{B}$, respectively. 
The crystalline phase of products was identified using X-ray diffraction (B8 ADVANCE, BRUKER X-ray diffractometer) patterns were recorded in step scanning on a by using CuKa radiation $(\lambda=1.54 \AA)$ and a scan rate of $1.5^{\circ} \cdot \mathrm{min}^{-1}$. IR reflection spectroscopy was performed with a RAYLEIGH WQF-510 spectrometer in the range $1000-4000 \mathrm{~cm}^{-1}$ at room temperature. The morphology and nanostructure were observed using a field emission scanning electron microscope (FESEM, HITACHI S-4160 XL30). The specific surface area of synthesised samples was determined using BEL SORP, MINI II-310 analyser. In this technique the Brunauer-Emmett-Teller (BET) equation was employed to calculate the specific surface area and the mean sizes of pores were calculated using the original Barrett, Joyner, and Halenda (BJH) method.

\section{RESULTS AND DISCUSSION}

The phase structure and purity of the products were examined by XRD. Figure 1a shows the XRD patterns of typical samples prepared with different $\mathrm{pH}$ adjusting regents. When compared to the standard pattern (JCPDS card no. 001-1283), the reflections of both the products were readily indexed to the orthorhombic boehmite phase, the XRD peaks at 14.39, 28.13, 38.23, 48.93, $51.59,54.94,60.03,63.69,64.68,66.76$ and 72.03 can be attributed to the (020), (120), (140), (131), (200), (160), (151), (211), (231), (071) and (251) planes of the boehmite structure, respectively. Furthermore, no characteristic peaks from other crystalline impurities were detected by XRD, suggesting that high purity of the boehmite samples. The high peak intensity and narrow peak width indicate the good crystallinity of the both sample, especially boehmite synthesized with $\mathrm{NaOH}$.

The crystallite sizes were calculated the using Scherrer equation:

$$
\mathrm{D}=(k \cdot \lambda) /(B \cdot \cos \theta)
$$

where $k$ is a constant $\sim 0.9, \lambda$ is the wavelength of the X-rays, $B$ is the full width of diffraction peak at half maximum intensity and $\theta$ is the Bragg angle. By using all the diffraction peaks in the XRD pattern, the calculated average crystallite sizes of B-N, B-K samples were 16 and $13 \mathrm{~nm}$, respectively. Comparison of XRD patterns of the prepared samples showed that the extent and percentage of crystallinity of samples do not differ significantly. These results indicated that the $\mathrm{NaOH}$ and $\mathrm{KOH}$ have a low influence on the crystallite phase of the samples.

Figure $1 \mathrm{~b}$ exhibits FTIR spectrums of the synthesized boehmite nanostructures. For both sample the FTIR spectra were similar regardless of the difference in intensity peaks. As shown in Figure 2a, for the B-N, five strong bands at 480, 630, 746, 1064, and $1171 \mathrm{~cm}^{-1}$ were observed. As can be seen, for both samples, the intensive bands at 3092 and $3300 \mathrm{~cm}^{-1}$ belong to the $v_{\text {as }}(\mathrm{Al}) \mathrm{O}-\mathrm{H}$ and $v_{s}(\mathrm{Al}) \mathrm{O}-\mathrm{H}$ stretching vibrations [21]. The two weak bands at 1970 and $2090 \mathrm{~cm}^{-1}$ are the combination bands. The absorption edge of the hydroxyl bands on the surface was found at $1636 \mathrm{~cm}^{-1}$, and this absorbance in the spectra of $\mathrm{AlOOH}$ nanoarchitectures are very weak, indicating a very small amount of physically adsorbed water molecules.

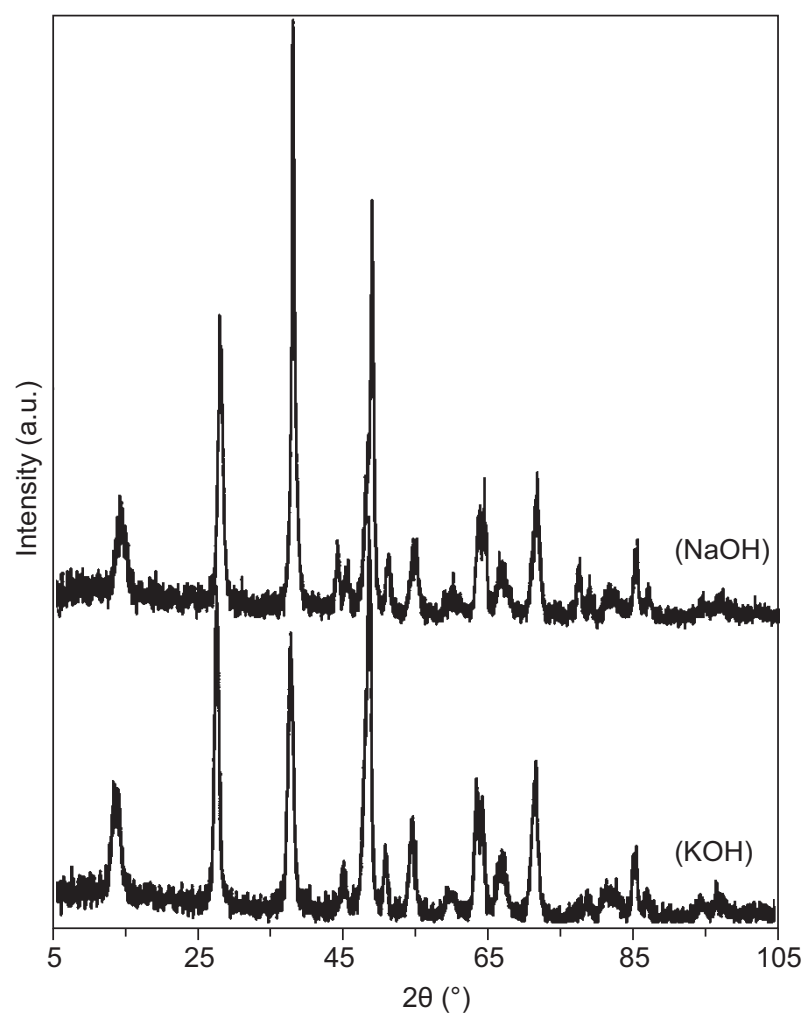

a)

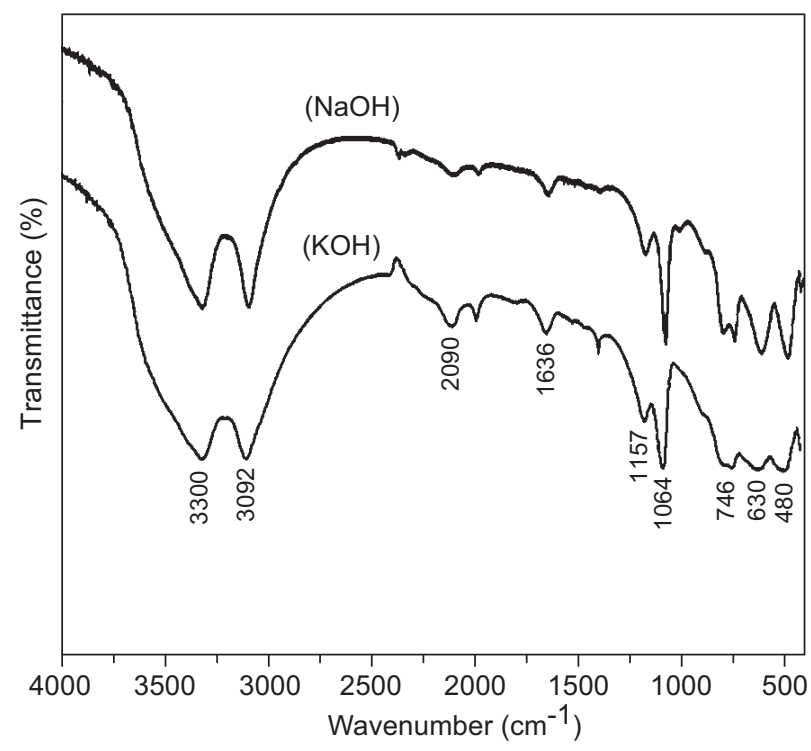

b)

Figure 1. XRD patterns (a) and FTIR spectra (b) of as-synthesized samples. 
The morphologies of the as-prepared boehmite samples in this work were examined by using FESEM analysis. Figure 2 shows the representative FESEM images of B-N (a) and B-K (b) samples. However, Figure $2 \mathrm{a}$ indicated that hierarchically nanostructures were more densely assembled by platelets and sheets, when $\mathrm{NaOH}$ was used for synthesis of boehmite. In this case a typical hierarchically nanostructures were built up by nano-sheets and nano-plates with average thickness of about $35 \mathrm{~nm}$. Generally, changes in $\mathrm{pH}$ adjusting regents from $\mathrm{NaOH}$ to $\mathrm{KOH}$ may favour to the formation process of nanoparticles. It can be found in Figure $2 b$ that there were only irregular nano particles that the size of particles was from 30 to $100 \mathrm{~nm}$, which the average size of the them was about $65 \mathrm{~nm}$.

BET $\mathrm{N}_{2}$ adsorption-desorption analysis was used to determine the specific surface area and pores size distribution in the boehmite nanostructures at $77 \mathrm{~K}$. As shown in Figure 3a, the typical adsorption-desorption isotherms of the $\mathrm{B}-\mathrm{N}$ and $\mathrm{B}-\mathrm{K}$ samples ascertained to be of type IV, according to the International Union of Pure and Applied Chemistry (IUPAC) classification, which is characteristic of mesoporous materials [27]. The adsorption-desorption isotherms of $\mathrm{B}-\mathrm{N}$ sample have a distinct $\mathrm{H} 3$ hysteresis loop in the relative pressure $\left(\mathrm{P} / \mathrm{P}_{0}\right)$ range of $0.57-1.0$, which indicates that the pore size distribution is not uniform. The adsorptiondesorption isotherms of $\mathrm{B}-\mathrm{K}$ sample have a distinct $\mathrm{H} 1$ hysteresis loop in the relative pressure $\left(\mathrm{P} / \mathrm{P}_{0}\right)$ range of $0.6-0.9$, which means that holes have been formed by stacking nano particles. Those results agree with the conclusions we discussed in the structure and morphology characterization section. The specific surface area calculated of the B-N and $\mathrm{K}-\mathrm{N}$ based on the BrunauerEmmett-Teller (BET) model are 144 and $55 \mathrm{~m}^{2} \cdot \mathrm{g}^{-1}$ and the pore volume determined by the BJH approaches are 1.23 and $0.18 \mathrm{~cm}^{3} \cdot \mathrm{g}^{-1}$, respectively. Obviously, the specific surface area and pore volume of $\mathrm{B}-\mathrm{N}$ is extremely larger than the B-K. Figure $3 \mathrm{~b}$ shows the BarrettJoyner-Halenda (BJH) calculations for the pore-size
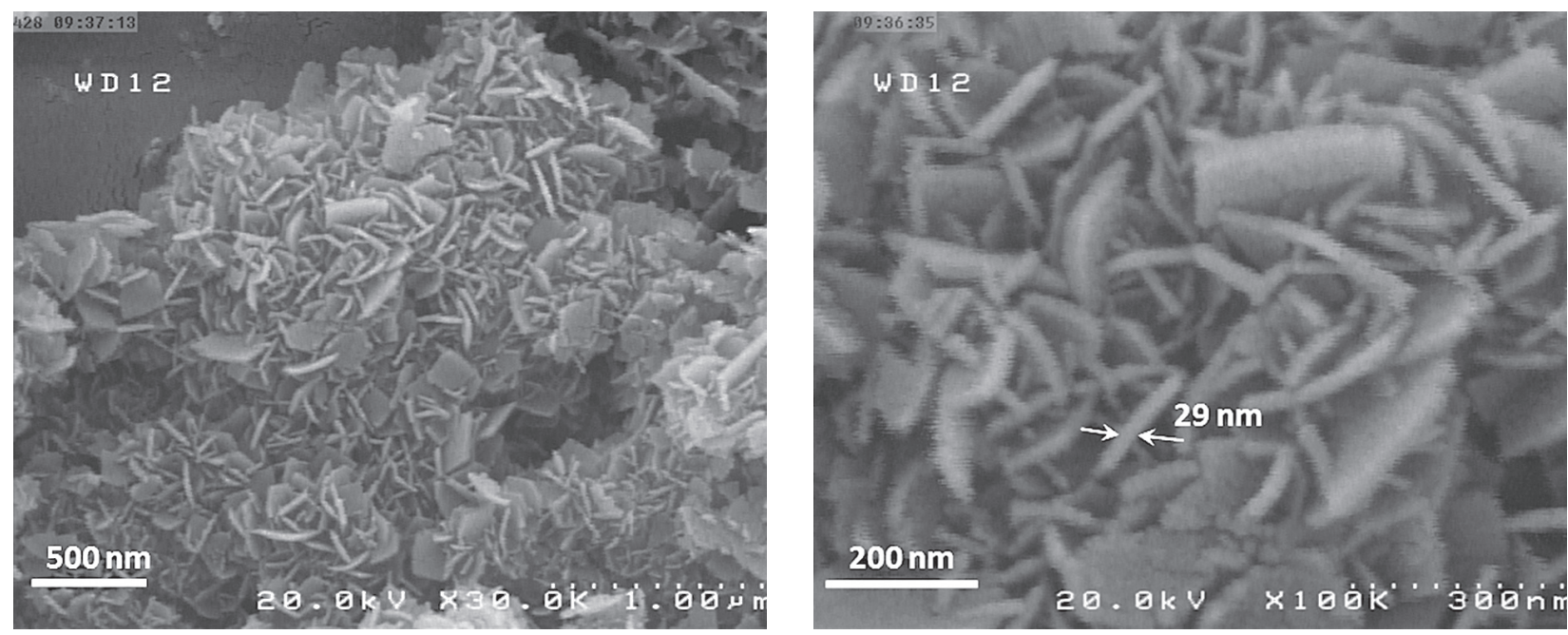

a)
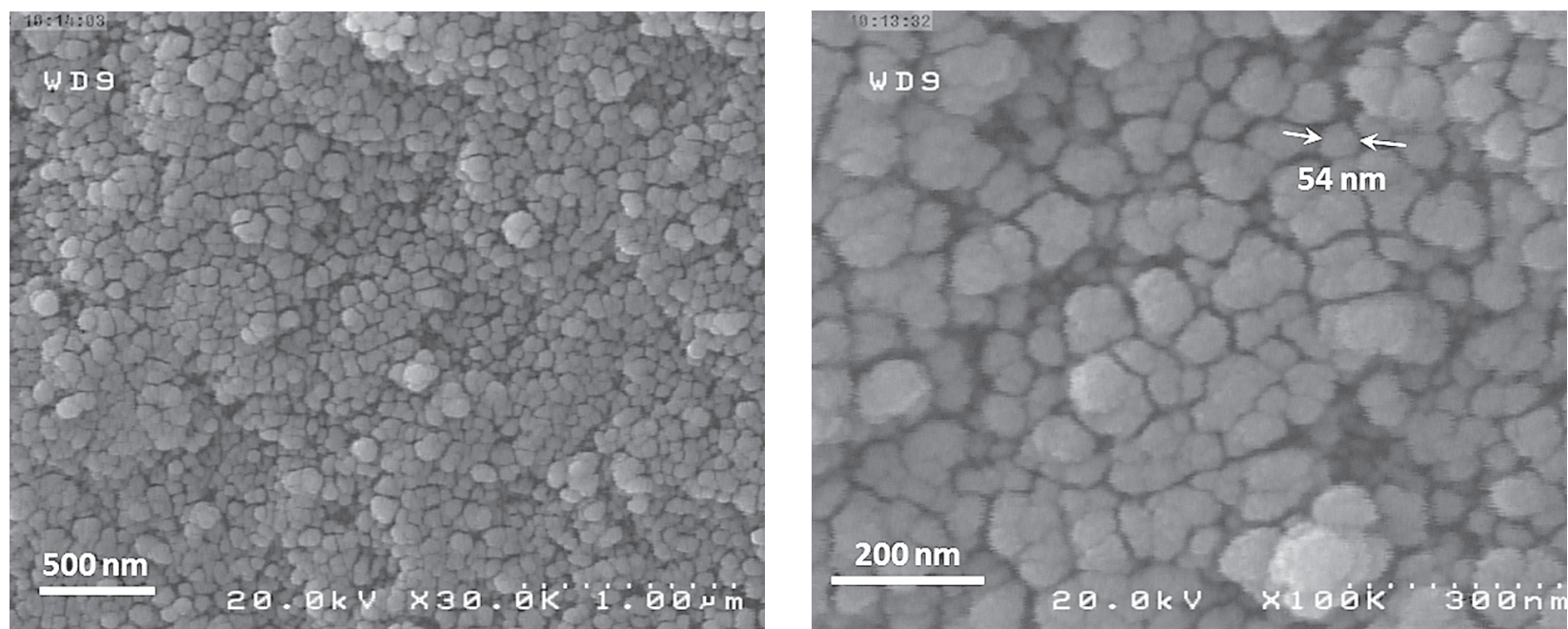

b)

Figure 2. FESEM images of the (a) B-N, (b) B-K samples.

Ceramics - Silikáty 60 (4) 273-277 (2016) 
distribution, derived from desorption data, revealed a narrow distribution centred at $4 \mathrm{~nm}$ for the $\mathrm{B}-\mathrm{K}$ and a wide range $2-50 \mathrm{~nm}$ for the $\mathrm{B}-\mathrm{N}$. The results display that the obtained boehmite products have excellent porous properties.

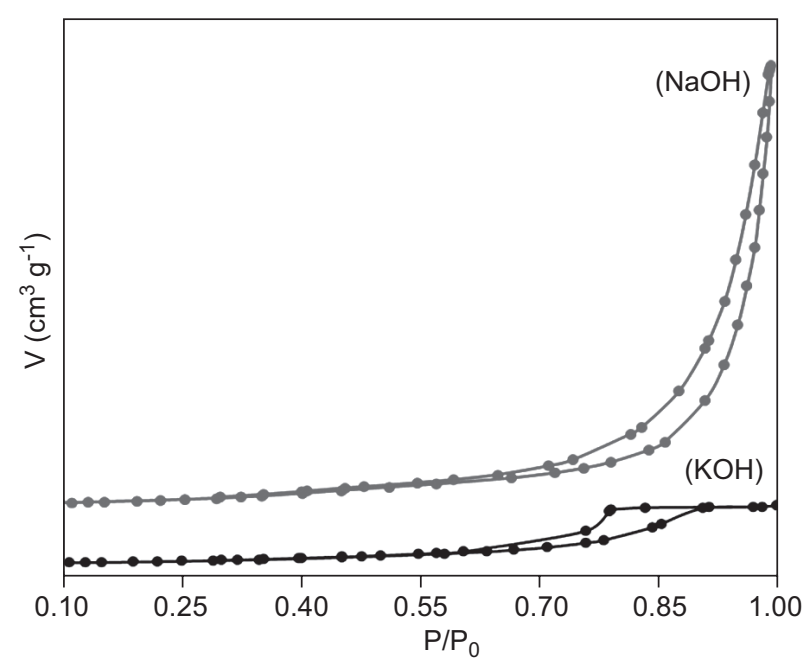

a)

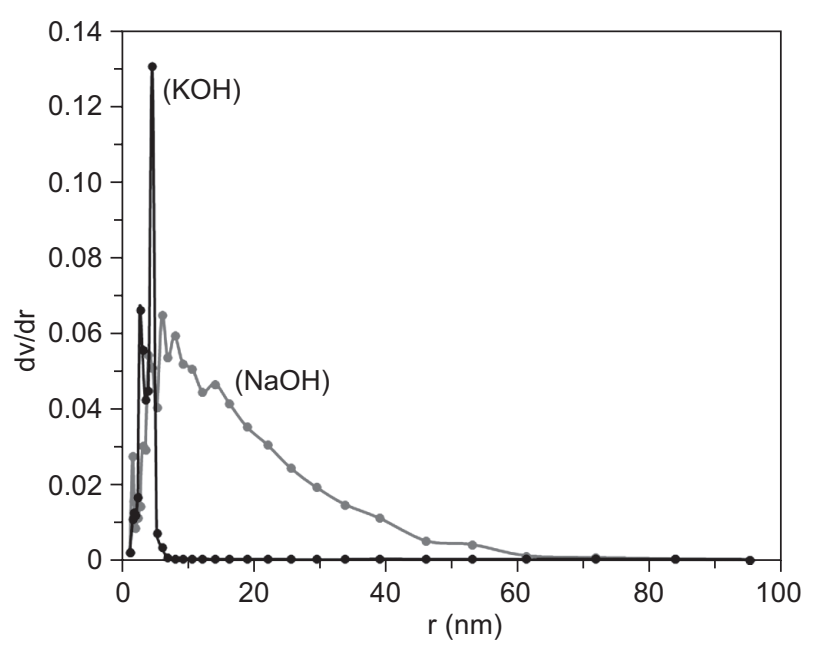

b)

Figure 3. Nitrogen adsorption-desorption isotherm (a) and the corresponding pore size distribution (b) curve for samples.

\section{CONCLUSIONS}

In summary, boehmite with nanostructure and nanoparticle morphologies has been successfully synthesized via simple solvothermal route. The effect of $\mathrm{NaOH}$ and $\mathrm{KOH}$ as $\mathrm{pH}$ adjusting agent on the synthesized samples were systematically studied and tested by several techniques. The morphology and texture evolutions of samples were investigated by changing the $\mathrm{pH}$ adjusting regents. Our results showed that the boehmite nanostructures with large surface area and higher pore volume were obtained when $\mathrm{NaOH}$ as $\mathrm{pH}$ adjusting agent was used. Meanwhile, these ordered mesoporous $\mathrm{AlOOH}$ nanostructures have potential applications for preparing ceramics, catalysts and adsorbents

\section{Acknowledgements}

The authors gratefully acknowledge the supports from Islamic Azad University, Kermanshah Branch.

\section{REFERENCES}

1. Abdollahifar M., Zamani R.M., Beiygie E., Nekouei H. (2014): Synthesis of micro-mesopores flowerlike $\gamma-\mathrm{Al}_{2} \mathrm{O}_{3}$ nano-architectures. Journal of the Serbian Chemical Society, 79(8), 1007-1017. doi:10.2298/JSC130903007A

2. Prakasam B.A., Lahtinen M., Muruganandham M., Sillanpää M. (2015): Synthesis of self-assembled $\alpha-\mathrm{GaOOH}$ microrods and 3D hierarchical architectures with flower like morphology and their conversion to $\alpha-\mathrm{Ga}_{2} \mathrm{O}_{3}$. Materials Letters, 158, 370-372. doi:10.1016/j.matlet.2015.05.044

3. Wang W., Pan H., Shi Y., Pan Y., Yang W., Liew, K. Song L., Hu Y., (2016): Fabrication of LDH nanosheets on $\beta-\mathrm{FeOOH}$ rods and applications for improving the fire safety of epoxy resin. Composites Part A: Applied Science and Manufacturing, 80, 259-269. doi:10.1016/j. compositesa.2015.10.031

4. Sigg L., Stumm W. (1981): The interaction of anions and weak acids with the hydrous goethite $(\alpha-\mathrm{FeOOH})$ surface. Colloids and Surfaces, 2(2), 101-117. doi:10.1016/01666622(81)80001-7

5. Tessier A., Fortin D., Belzile N., DeVitre R., Leppard G. (1996): Metal sorption to diagenetic iron and manganese oxyhydroxides and associated organic matter: narrowing the gap between field and laboratory measurements. Geochimica et Cosmochimica Acta, 60(3), 387-404. doi:10.1016/0016-7037(95)00413-0

6. Zhang Y.C., Wu X., Hu X.Y., Shi Q.F. (2007): A green hydrothermal route to $\mathrm{GaOOH}$ nanorods. Materials Letters, 61(7), 1497-1499. doi:10.1016/j.matlet.2006.07.060

7. Li G., Peng C., Li C., Yang P., Hou Z., Fan Y., Cheng Z., Li, J. (2010): Shape-controllable synthesis and morphologydependent luminescence properties of $\mathrm{GaOOH}: \mathrm{Dy}^{3+}$ and $\beta-\mathrm{Ga}_{2} \mathrm{O}_{3}: \mathrm{Dy}^{3+}$. Inorganic Chemistry, 49(4), 1449-1457. doi:10.1021/ic901682x

8. Wang B., Wu H., Yu L., Xu R., Lim T.T. (2012): Templatefree Formation of Uniform Urchin like $\alpha$-FeOOH Hollow Spheres with Superior Capability for Water Treatment. Advanced Materials, 24(8), 1111-1116. doi:10.1002/adma. 201104599

9. Abdollahifar M. (2014): Synthesis and characterisation of $\gamma-\mathrm{Al}_{2} \mathrm{O}_{3}$ with porous structure and nanorod morphology. Journal of Chemical Research, 38(3), 154-158. doi:10.3 184/174751914X13910938972748

10.Haghnazari N., Abdollahifar M., Jahani F. (2014): The Effect of $\mathrm{NaOH}$ and $\mathrm{KOH}$ on the Characterization of Meso-porous AlOOH Nanostructures in the Hydrothermal Route. Journal of the Mexican Chemical Society, 58(2), 95-98.

11. Rahimi S., Moattari R.M. Rajabi L., Derakhshan A.A., Keyhani M. (2015): Iron oxide/hydroxide $(\alpha, \gamma$-FeOOH) nanoparticles as high potential adsorbents for lead remo- 
val from polluted aquatic media. Journal of Industrial and Engineering Chemistry, 23, 33-43. doi:10.1016/j.jiec. 2014.07.039

12. Abdollahifar M., Haghighi M., Babaluo A.A. (2014): Syngas production via dry reforming of methane over $\mathrm{Ni} / \mathrm{Al}_{2} \mathrm{O}_{3}-\mathrm{MgO}$ nanocatalyst synthesized using ultrasound energy. Journal of Industrial and Engineering Chemistry, 20(4), 1845-1851. doi:10.1016/j.jiec.2013.08.041

13. Baneshi J., Haghighi M., Jodeiri N., Abdollahifar M., Ajamein H. (2014): Homogeneous precipitation synthesis of $\mathrm{CuO}-\mathrm{ZrO}_{2}-\mathrm{CeO}_{2}-\mathrm{Al}_{2} \mathrm{O}_{3}$ nanocatalyst used in hydrogen production via methanol steam reforming for fuel cell applications. Energy Conversion and Management, 87, 928-937. doi:10.1016/j.enconman.2014.07.058

14. Baneshi J., Haghighi M., Jodeiri N., Abdollahifar M., Ajamein H. (2014): Urea-nitrate combustion synthesis of $\mathrm{ZrO}_{2}$ and $\mathrm{CeO}_{2}$ doped $\mathrm{CuO} / \mathrm{Al}_{2} \mathrm{O}_{3}$ nanocatalyst used in steam reforming of biomethanol for hydrogen production. Ceramics International, 40(9), 14177-14184. doi:10.1016/j. ceramint.2014.06.005

15. Belhouchet H., Hamidouche M., Bouaouadja N., Garnier V., Fantozzi G. (2009): Elaboration and characterization of mullite-zirconia composites from gibbsite, boehmite and zircon. Ceramics-Silikaty, 53(3), 205-210.

16. Bodišová K., Pach L., Kovar V., (2005): The influence of the preferred orientation of boehmite crystallites on $\alpha-\mathrm{Al}_{2} \mathrm{O}_{3}$ crystallization. Ceramics-Silikáty, 49(1), 34-39.

17. Yahyavi S.R., Haghighi M., Shafiei S., Abdollahifar M., Rahmani F. (2015): Ultrasound-assisted synthesis and physicochemical characterization of $\mathrm{Ni}-\mathrm{Co} / \mathrm{Al}_{2} \mathrm{O}_{3}-\mathrm{MgO}$ nanocatalysts enhanced by different amounts of $\mathrm{MgO}$ used for $\mathrm{CH}_{4} / \mathrm{CO}_{2}$ reforming. Energy Conversion and Management, 97, 273-281. doi:10.1016/j.enconman.2015. 03.064

18. Zhang X., Wu Y., Liu G., He S., Yang D. (2008): Investigation on sol-gel boehmite-AlOOH films on Kapton and their erosion resistance to atomic oxygen. Thin Solid Films,
516(15), 5020-5026. doi:10.1016/j.tsf.2008.01.023

19. Hou H., Xie Y., Yang Q., Guo Q., Tan C. (2005): Preparation and characterization of $\gamma-\mathrm{AlOOH}$ nanotubes and nanorods. Nanotechnology, 16(6), 741. doi:10.1088/0957-4484/ 16/6/019

20. Abdollahifar M., Karami A.R., Haghnazari N., Karami C. (2015): Synthesis of porous boehmite nanostructures: effects of time and temperature in the hydrothermal method. Ceramics-Silikáty, 59(4), 305-310.

21. Ameri E. Abdollahifar M., Zamani M.R., Nekouei H. (2016): The role of urea on the hydrothermal synthesis of boehmite nanoarchitectures. Ceramics-Silikáty, 60(2), 162168. doi: $10.13168 / \mathrm{cs} .2016 .0025$

22. Li G., Liu Y., Liu D., Liu L., Liu C. (2010): Synthesis of flower-like Boehmite $(\mathrm{AlOOH})$ via a simple solvothermal process without surfactant. Materials Research Bulletin, 45(10), 1487-1491. doi:10.1016/j.materresbull.2010.06.013

23. Holkova Z., Pach L., Majling J., Kakos J., Kadlecikova M. (2003): Effect of organic additives on crystallization of boehmite gels. Ceramics- Silikaty, 47(4), 149-154.

24. Zhao X., Ji X., Zhang Y., Lu B. (2004): Effect of solvent on the microstructures of nanostructured $\mathrm{Bi}_{2} \mathrm{Te}_{3}$ prepared by solvothermal synthesis. Journal of Alloys and Compounds, 368(1), 349-352. doi:10.1016/j.jallcom.2003.08.070

25. Chen X.Y., Huh H.S., Lee S.W. (2007): Hydrothermal synthesis of boehmite $(\gamma-\mathrm{AlOOH})$ nanoplatelets and nanowires: pH-controlled morphologies. Nanotechnology, 18(28), 285608. doi:10.1088/0957-4484/18/28/285608

26. Hicks R.W., Pinnavaia T.J. (2003): Nanoparticle assembly of mesoporous $\mathrm{AlOOH}$ (boehmite). Chemistry of Materials, 15(1), 78-82. doi:10.1021/cm020753f

27. Sing K.S.W., Everett D.H., Haul R.A.W. Moscou L., Pierotti R.A., Rouquerol J., Siemieniewska T. (1985): Reporting physisorption data for gas/solid systems - with special reference to the determination of surface area and porosity. Pure and Applied Chemistry, 57(4), 603-619.doi:10.1351/ pac198557040603 